\title{
Adapting the Residential Daylight Score for Arid, Hot, and Humid Climates
}

\author{
Ye Chan Park ${ }^{1}$, Timur Dogan ${ }^{1}$ \\ ${ }^{1}$ Environmental Systems Lab, Cornell University, Ithaca, New York, USA
}

\begin{abstract}
Access to direct light is often considered a desirable quality in residential architecture. A novel daylighting performance metric called the Residential Daylight Score (RDS) has been suggested for cold and temperate climates to monitor diurnal and seasonal fluctuations in both daylight and access to direct light. However, direct light can significantly influence heating and cooling loads, and more research that correlates direct light with its thermal contributions is needed to make daylighting recommendations for warmer climates. As of now, residential daylight evaluation remains difficult in arid, hot, and humid climates, in which the effect of direct light on cooling loads is the largest. The authors juxtapose access to direct light with thermal and daylighting contributions across 14 different climate zones. The authors then propose a climate-based schema that considers thermal implications of daylight in residential architecture to adapt the RDS for use in warmer climates.
\end{abstract}

\section{Introduction}

The benefit of direct light in residential architecture has been long discussed in the European context. Since the beginning of the early twentieth century, architectural design guidelines, such as those by Neufert (Neufert \& Neufert, 2012), have emphasized that domestic programs should be oriented toward the changing direction of direct light throughout the day. Several European countries provide regulations or guidelines to stipulate that each residential unit have access to direct light (German Institute for Standardization, DIN., 1999), which is regarded as an essential qualitative parameter for passive heating in dense urban neighborhoods with limited solar exposure on the façade (StrømannAndersen \& Sattrup, 2011). Even in warmer climates, access to direct light significantly influences the efficiency of vitamin D synthesis in the human body. Studies show that changes in contemporary Middle Eastern housing design that omit private outdoor spaces, such as courtyards, can be directly correlated with Vitamin D deficiencies in the female population (Fonseca, Tongia, el-Hazmi, \& Abu-Aisha, 1984; Alagöl et al., 2000). Direct light is also needed to create physiologically and visually stimulating luminous environments (Andersen, Mardaljevic, \& Lockley, 2012; Rockcastle \& Andersen, 2014). As evident through these benefits, evaluation techniques that acknowledge the positive effects of direct light in the residential setting are needed.

\section{Residential Daylight Score}

The Residential Daylight Score (RDS) was introduced as the first residential architecture-specific daylighting performance metric (DPM) that rewards the incidence of direct light (Direct Light Access, DLA) and evaluates general daylight supply (Residential Daylight Autonomy, RDA) (Dogan \& Park, 2017; Dogan \& Park, 2018). To account for seasonal and diurnal fluctuations in daylight, both the RDA and the DLA are evaluated in 12 timeframes (4 seasons and morning, noon, and evening). For each timeframe, the RDA evaluates whether a residential unit receives sufficient daylight $(\geq 3001 x)$ for $50 \%$ or more of daytime hours, based on thresholds for the Spatial Daylight Autonomy (sDA) (IESNA, 2012). The DLA evaluates the duration of direct sunlight access in a residential unit for each of the 12 timeframes. Finally, a composite RDS score is computed, with a maximum of 24 points (Figure 1). As the RDS assumes the presence of direct light in the interior to be beneficial, it was recommended for use only in cold and temperate climates, where passive solar heating is desirable and overheating in summer months is less of a concern.

\section{Direct Light, Cooling Loads, and Glare}

Because of its potential to increase cooling loads during warm months and impact occupant comfort (Utzinger \& Wasley, 1997; Bennet \& O’Brien, 2017), expectations and occupant response to direct light will differ in warmer climates. Intuitively, the value of direct light on an autumn day in Anchorage is much higher than that on the same day in Miami.

However, much of the research addressing the negative impacts of direct light have focused on completely blocking out direct light from the interior (typically
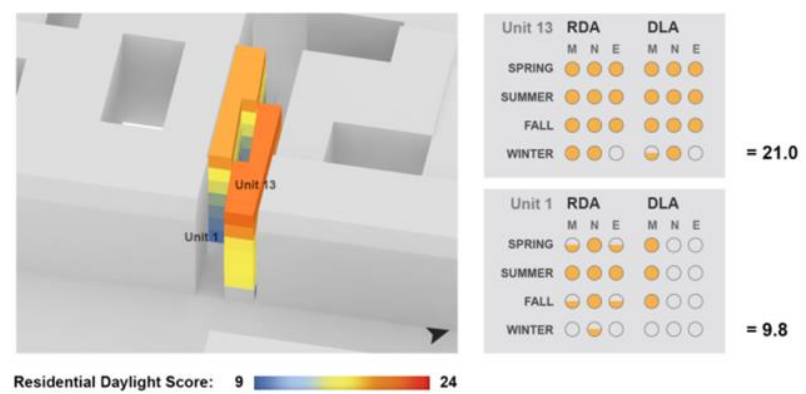

Figure 1: Residential Daylight Score 
office spaces) to reduce visual glare, either with viewbased glare probability metrics (Wienold \& Christoffersen, 2006; Wienold, 2009; Jakubiec \& Reinhart, 2012) or floor-plan-based oversupply metrics (Nabil \& Mardaljevic, 2005; Mardaljevic, Andersen, Roy, \& Christoffersen, 2011; IESNA, 2012). However, glare may be a less serious problem in the residential context, as occupants have an increased ability to change their orientation and posture and to control the shading in their environments (Jakubiec \& Reinhart, 2012; Xue, Mak, \& Cheung, 2014). In many cases, overheating due to direct light is a larger concern to residents than visual glare (Bennet, O’Brien, \& Gunay, 2014).

Meanwhile, other studies have acknowledged the importance of balancing daylight (and more specifically, direct light) with its thermal impacts, and various proposals have been made to present the two kinds of data side-by-side (De Groot, Zonneveldt, Paule, \& SA, 2003; Franzetti, Fraisse, \& Achard, 2004; Hviid, Nielsen, \& Svendsen, 2008). Reinhart and Wienold have proposed a "daylighting dashboard" that separately evaluates the daylight autonomy, occupant comfort (visual glare and view), and energy costs of space, modeled both with and without blinds (2011). StrømannAndersen and Sattrup have noted that increased urban density moderately increases heating energy loads due to decreased exposure to direct light (2011). Kleindienst and Andersen have proposed three side-by-side, goalbased metrics that evaluate illuminance, glare, and solar heat gain (2012). Other studies address the effects of different kinds of shading schedules and thresholds on the artificial lighting, cooling, and heating energy loads of interior space in a specific climate (Nielsen, Svendsen, \& Jensen, 2011; Shen \& Tzempelikos, 2012).

Many of these studies and metrics acknowledge that daylighting performance must be understood not only in terms of providing sufficient daylight supply but also in the increase in cooling loads due to passive solar heat gain. However, a broader consensus on how to evaluate direct light in dwelling units with respect to its thermal impact still needs to be found.

Exhaustively defining the relationship between daylight performance and thermal implications is a difficult task, due to a large number of parametric possibilities in defining the experimental space, its construction and fenestration type, and other geometric variables. Nevertheless, the authors propose an energy simulationbased framework to study this relationship across 14 major climate zones and to inform a proof-of-concept adaptation of the DLA so that direct light in an apartment is considered beneficial only when it either decreases heating energy loads or does not increase cooling loads.

\section{Methods}

The authors indicate 14 climate zones defined by ASHRAE 90.1 2013 (ASHRAE, 2014) (Table 1). For each climate zone, example cities according to ASHRAE definitions and their corresponding latitudes are listed.
Table 1: ASHRAE climate zones

\begin{tabular}{|c|c|c|c|}
\hline Zone & $\begin{array}{c}\text { Climate } \\
\text { Zone Name }\end{array}$ & Example Cities & Latitude \\
\hline \multirow{2}{*}{$1 \mathrm{~A}$} & \multirow{2}{*}{$\begin{array}{l}\text { Very Hot- } \\
\text { Humid }\end{array}$} & Miami & $25^{\circ} 47^{\prime} \mathrm{N}$ \\
\hline & & Singapore & $1^{\circ} 17^{\prime} \mathrm{N}$ \\
\hline \multirow{2}{*}{$2 \mathrm{~A}$} & \multirow{2}{*}{ Hot-Humid } & Houston & $29^{\circ} 46^{\prime} \mathrm{N}$ \\
\hline & & Hong Kong & $22^{\circ} 17^{\prime} \mathrm{N}$ \\
\hline \multirow{2}{*}{$2 \mathrm{~B}$} & \multirow{2}{*}{ Hot-Dry } & Phoenix & $33^{\circ} 27^{\prime} \mathrm{N}$ \\
\hline & & Cairo & $30^{\circ} 3 \mathrm{~N}$ \\
\hline \multirow{2}{*}{$3 \mathrm{~A}$} & \multirow{2}{*}{ Warm-Humid } & Atlanta & $33^{\circ} 45^{\prime} \mathrm{N}$ \\
\hline & & Tel Aviv & $32^{\circ} 04^{\prime} \mathrm{N}$ \\
\hline \multirow{2}{*}{$3 \mathrm{~B}$} & \multirow{2}{*}{ Warm-Dry } & Los Angeles & $34^{\circ} 03^{\prime} \mathrm{N}$ \\
\hline & & Mexico City & $19^{\circ} 26^{\prime} \mathrm{N}$ \\
\hline \multirow{2}{*}{$3 \mathrm{C}$} & \multirow{2}{*}{ Warm-Marine } & San Francisco & $37^{\circ} 47^{\prime} \mathrm{N}$ \\
\hline & & Cape Town & $33^{\circ} 56^{\prime} \mathrm{S}$ \\
\hline \multirow{2}{*}{$4 \mathrm{~A}$} & \multirow{2}{*}{ Mixed-Humid } & New York & $40^{\circ} 40^{\prime} \mathrm{N}$ \\
\hline & & Seoul & $37^{\circ} 34^{\prime} \mathrm{N}$ \\
\hline $4 B$ & Mixed-Dry & Albuquerque & $35^{\circ} 07^{\prime} \mathrm{N}$ \\
\hline $4 \mathrm{C}$ & $\begin{array}{l}\text { Mixed- } \\
\text { Marine }\end{array}$ & Seattle & $47^{\circ} 37^{\prime} \mathrm{N}$ \\
\hline \multirow{2}{*}{$5 \mathrm{~A}$} & \multirow{2}{*}{ Cool-Humid } & Chicago & $41^{\circ} 53{ }^{\prime} \mathrm{N}$ \\
\hline & & Munich & $48^{\circ} 08^{\prime} \mathrm{N}$ \\
\hline $5 \mathrm{~B}$ & Cool-Dry & Denver & $39^{\circ} 44^{\prime} \mathrm{N}$ \\
\hline \multirow{2}{*}{$6 \mathrm{~A}$} & \multirow{2}{*}{ Cold-Humid } & Minneapolis & $44^{\circ} 59^{\prime} \mathrm{N}$ \\
\hline & & Moscow & $46^{\circ} 44^{\prime} \mathrm{N}$ \\
\hline $6 \mathrm{~B}$ & Cold-Dry & Helena & $46^{\circ} 36^{\prime} \mathrm{N}$ \\
\hline 7 & Very Cold & Anchorage & $61^{\circ} 13^{\prime} \mathrm{N}$ \\
\hline
\end{tabular}

The authors create a shoebox with the dimensions of $6 \mathrm{~m}$ $\mathrm{x} 10 \mathrm{~m} \times 3 \mathrm{~m}$ and a floor area of $60 \mathrm{~m}^{2}$ as the test space. The shoebox has a single South-facing window. All surfaces, except the façade, are adiabatic. A fully conditioned space with a low air change rate $(\mathrm{ACH}=$ 0.3 ) and no natural ventilation is assumed. While the lack of natural ventilation may result in an overestimation of cooling loads, the creation of a nearly airtight design space allows the calculation of pure (or "theoretical") heating and cooling loads solely based on climate, construction, and geometry. Potential cooling by natural ventilation would thus not be considered in this study.

For all climates, 4 levels of window-to-wall ratios (WWRs) are tested: 10\%, 30\%, 50\%, and 70\%.

For all WWRs, both "heavy" (concrete/masonry) and "light" (metal/timber frame) constructions are employed to account for differences in thermal loads. For each construction type, ASHRAE-defined U-values are used (ASHRAE, 2014) (Table 2).

4 shading types are then employed for all construction types. There is currently a lack of consensus on simulating residential blind usage. Therefore, sDA specifications for blind usage as specified by LM-83 (IESNA, 2012) were employed as a proxy. For a floor area of $60 \mathrm{~m}^{2}$, interior blinds must be drawn for all hours during which 5 or more of the floor grid sensors receive 
1000lx or more of direct light. The 4 shading types (Table 3) include: An external shade that completely blocks the incidence of direct light in the interior; no shading whatsoever; interior blinds according to the sDA protocol; and a $1 \mathrm{~m}$ balcony extrusion (a common feature in residential architecture) with interior blinds according to the sDA protocol.

Table 2: Heavy mass vs. light mass construction

\begin{tabular}{|c|c|c|c|c|}
\hline $\begin{array}{l}\text { Mass } \\
\text { Type }\end{array}$ & $\begin{array}{l}\text { Constr. } \\
\text { (exterior to } \\
\text { interior) }\end{array}$ & $\begin{array}{c}\text { Façade } \\
\text { U-val. } \\
\left(\mathbf{W} / \mathbf{m}^{2} \mathbf{K}\right)\end{array}$ & $\begin{array}{c}\text { Façade } \\
\text { Heat } \\
\text { Capacity } \\
\left(\mathbf{k J} / \mathbf{m}^{2} \mathbf{K}\right) \\
\end{array}$ & $\begin{array}{c}\text { Glazing } \\
\text { Specification }\end{array}$ \\
\hline $\begin{array}{c}\text { Heavy } \\
\text { mass }\end{array}$ & $\begin{array}{c}20 \mathrm{~mm} \\
\text { Gypsum / } \\
20-109 \mathrm{~mm} \\
\text { Foam Glass } \\
\text { Insulation / } \\
300 \mathrm{~mm} \\
\text { Concrete / } \\
20 \mathrm{~mm} \\
\text { Gypsum } \\
\end{array}$ & $\begin{array}{c}\text { U-0.404- } \\
0.857\end{array}$ & 731.4-738.6 & $\begin{array}{c}\text { U-1.820- } \\
2.840, \\
\text { Tvis } 0.65, \\
\text { SHGC } 0.27\end{array}$ \\
\hline $\begin{array}{l}\text { Light } \\
\text { mass }\end{array}$ & $\begin{array}{c}20 \mathrm{~mm} \\
\text { Gypsum / } \\
83-205 \mathrm{~mm} \\
\text { Foam Glass } \\
\text { Insulation / } \\
\text { 20mm } \\
\text { Gypsum }\end{array}$ & $\begin{array}{c}\text { U-0.248- } \\
0.533\end{array}$ & $52.1-64.0$ & $\begin{array}{c}\text { U-1.820- } \\
\text { 2.840, } \\
\text { Tvis } 0.65, \\
\text { SHGC } 0.27\end{array}$ \\
\hline
\end{tabular}

Table 3: Shading types

\begin{tabular}{|c|c|}
\hline Shading Type & Shading Condition \\
\hline Type A & $\begin{array}{c}\text { External shade that completely blocks } \\
\text { direct light }\end{array}$ \\
\hline Type B & No shading \\
\hline Type C & Dynamic interior blinds (sDA protocol) \\
\hline Type D & $\begin{array}{c}\text { 1m extrusion above window + Dynamic } \\
\text { interior blinds (sDA protocol) }\end{array}$ \\
\hline
\end{tabular}

In total, 448 shoeboxes (14 climate zones x 4WWRs x 2 constructions $\mathrm{x} 4$ shading types) are created. The authors acknowledge that this is only a preliminary set of variables; an expansion of variables to include other orientations and glazing layouts is eventually necessary.
The 448 shoeboxes are tested for percentage of daylit floor area (defined by the sDA and RDA), heating energy loads, theoretical cooling energy loads, and electric lighting energy loads. An electric heat-pump with a coefficient of performance (COP) of 3 is assummed for heating and cooling loads. DIVA4 is used for daylighting simulations (Solemma LLC., 2016), while Archsim is used for thermal simulations (Dogan, 2013). A summary of the workflow is found in Figure 2.

Daylighting and energy loads are summarized using the 12 time-bins from the RDS (Table 4) to facilitate a better understanding of seasonal and diurnal differences. Schedules for apartment occupancy, heating and cooling, electrical lighting, and equipment follow those of the U.S. Department of Energy (DOE) Reference Buildings, Midrise Apartment, v. 1.47 .2 (Department of Energy, 2004). All geometry, construction, and simulation parameters are provided in the Appendix.

Table 4: Diurnal and seasonal analysis timeframes that produce the 12 time-bins

\begin{tabular}{|c|c|c|c|}
\hline Morning & \multicolumn{2}{|c|}{ Noon } & Evening \\
\hline Sunrise-11 & \multicolumn{2}{|c|}{$11-15$} & 15-Sunset \\
\hline Spring & Summer & Fall & Winter \\
\hline $\begin{array}{l}\text { Feb/07- } \\
\text { May/06 }\end{array}$ & $\begin{array}{c}\text { May/07- } \\
\text { Aug/06 }\end{array}$ & $\begin{array}{c}\text { Aug/07- } \\
\text { Nov/06 }\end{array}$ & $\begin{array}{c}\text { Nov/07- } \\
\text { Feb/06 }\end{array}$ \\
\hline
\end{tabular}

\section{Results}

Figure 3 shows the impact of direct light on daylighting, heating loads, cooling loads, and electric lights loads through a comparison between no direct light in the interior (Shading Type A) to full exposure to direct light, with no exterior shading or interior blinds (Shading Type B).

Figure 4 shows a close-up of Heavy Mass: $50 \%$ WWR: Heating Load Changes: Winter as an example for how the chart is to be read: As the climate zones become colder, direct light further reduces heating loads (decrease shown in green), particularly during morning hours. The biggest reduction in this condition is seen during morning hours in the Cool-Dry climate (Denver, $39^{\circ} 44^{\prime} \mathrm{N}$ ), with a decrease in heating loads by
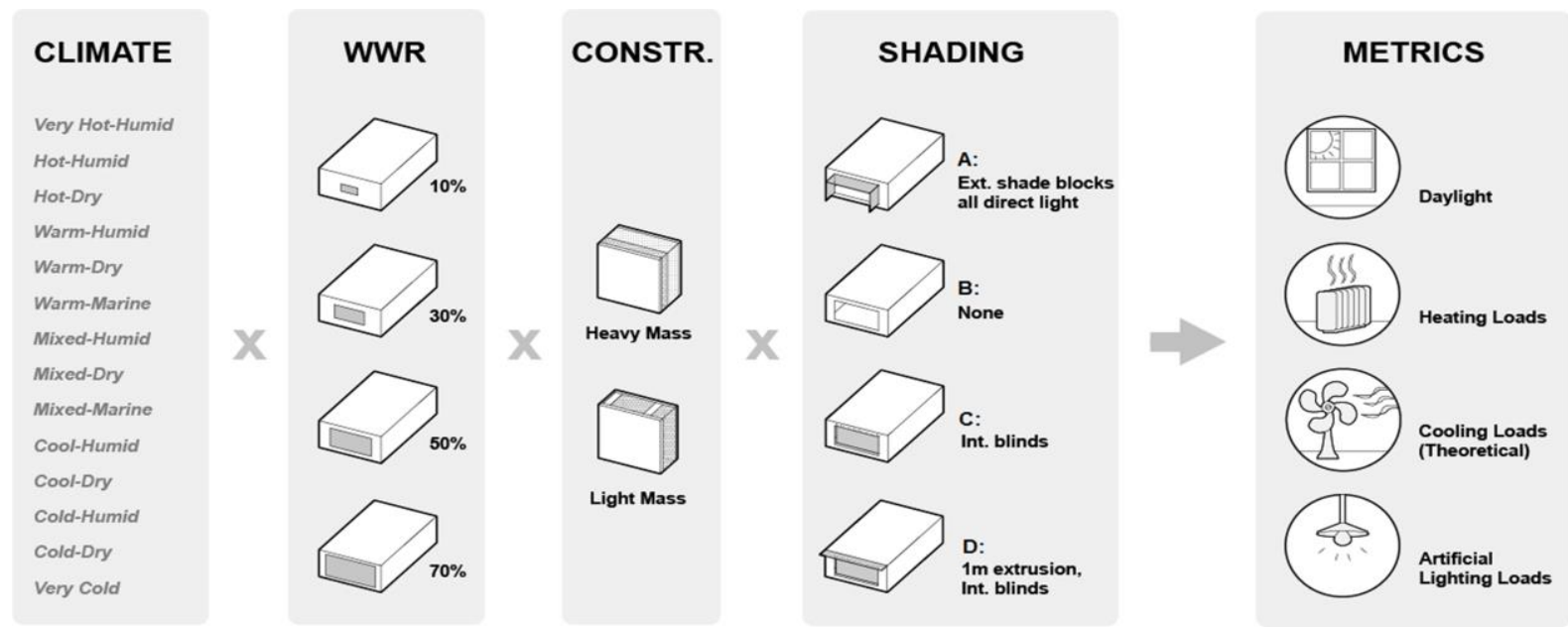


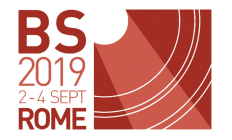

16th IBPSA

CONFERENCE
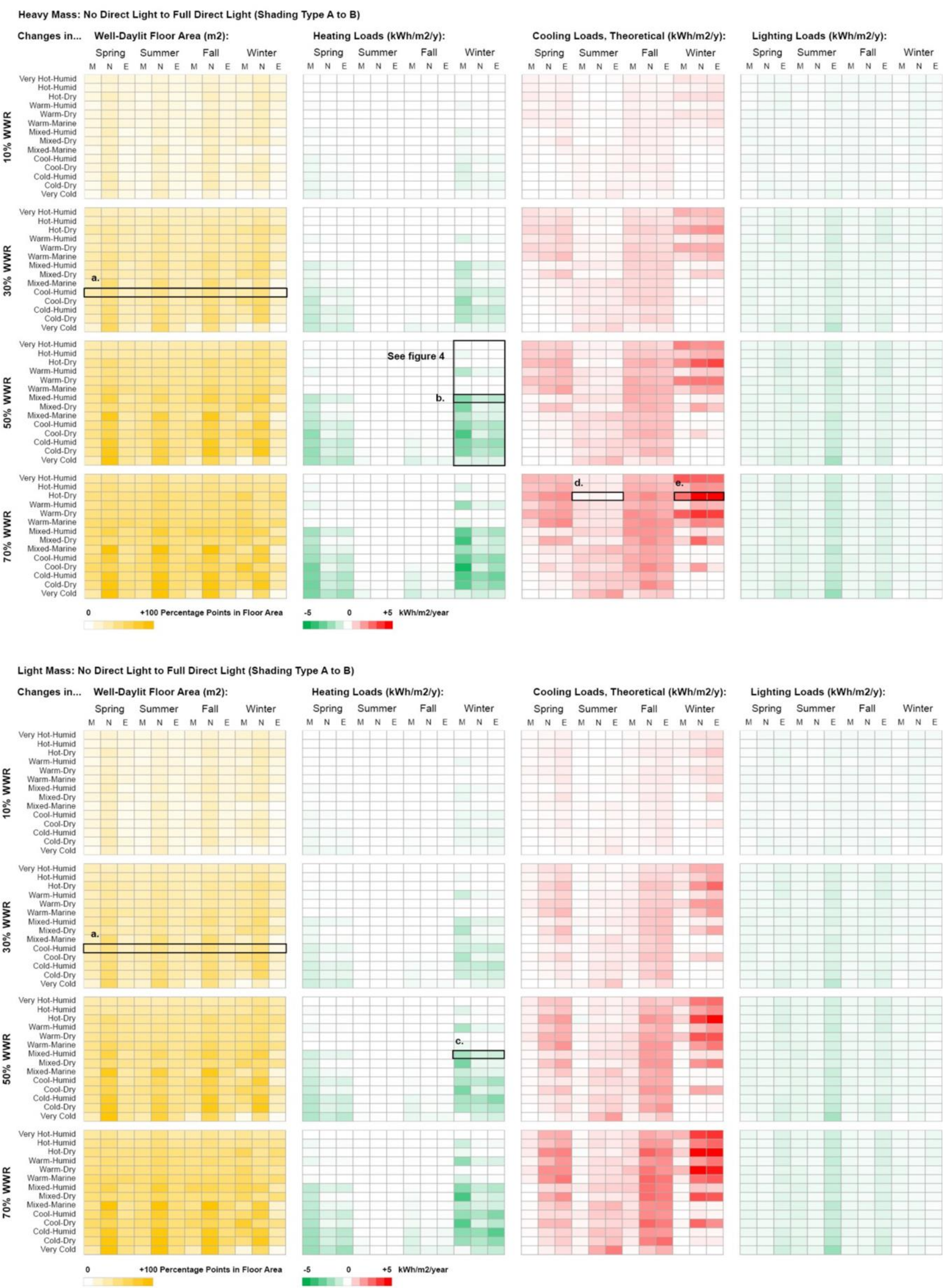

Figure 3: Changes in daylit floor area, heating loads, cooling loads, and artificial lighting loads by fully admitting direct light (i.e. transition from Shading Type A to Shading Type B). 
$3.8 / \mathrm{kWh} / \mathrm{m}^{2} /$ year. In Very Cold climates (Anchorage, $61^{\circ} 13^{\prime} \mathrm{N}$ ), however, there is a smaller reduction of heating loads, as thermal losses through the glazing are larger than thermal gains by direct light. The results in Figure 3 confirm a number of intuitive assumptions:

First, admitting direct light into the interior dramatically increases the daylit floor area, particularly during noon hours (given the southern orientation of the shoebox). For example, a shoebox with a $30 \%$ WWR in a CoolHumid climate (Chicago; $41^{\circ} 53^{\prime} \mathrm{N}$ ) will see an increase of more than $50 \%$ points in daylit areas during noon hours across the year (Figure 3-a); that is, during spring noon hours, there is an increase from $10 \%$ of the floor area being daylit to $64 \%$ of the floor area being daylit (thus $+54 \%$ points), and so forth. During morning and evening hours throughout the year in that climate, there will be moderate increases in the daylit area, except for winter evenings, during which there is an increase of only $15 \%$ points (Figure $3-a)$. The increase in daylit floor area will also slightly reduce artificial lighting loads, particularly during summer evenings and to a lesser degree in spring and fall evenings.

Second, direct light in the interior will decrease heating loads, particularly during spring and winter months in mixed to very cold climates. Increased WWR further reduces heating loads due to increased admittance of direct light in the interior. Similar trends, although slightly diminished, are observed in light-mass construction as well. For example, a shoebox with heavy construction and 50\% WWR in a Mixed-Humid climate (New York, $40^{\circ} 40^{\prime} \mathrm{N}$ ) sees heating loads reduced by 2.5 , 1.0 , and $1.4 \mathrm{kWh} / \mathrm{m}^{2} /$ year respectively during winter morning, noon, and evening (Figure 3-b). In a light construction of the same parameters, the heating loads are reduced by $1.9,0.9$, and $1.1 \mathrm{kWh} / \mathrm{m}^{2} /$ year respectively during the same time-bins (Figure 3-c).

Third, direct light in the interior will increase theoretical cooling loads throughout all climates, although during different seasons. Very hot to mixed climates will see heightened increases in cooling loads in winter months, during which solar altitude is lower. For example, a shoebox with heavy construction and 70\% WWR in a Hot-Dry climate (Phoenix, $33^{\circ} 27^{\prime} \mathrm{N}$ ) sees direct light increase theoretical cooling loads by roughly 3 to 5 $\mathrm{kWh} / \mathrm{m}^{2} /$ year during winter noon and evening (Figure 3e). Direct light will cause less increase in summer months when solar altitude is high: $0.2,0.3$, and 0.1 $\mathrm{kWh} / \mathrm{m}^{2} /$ year respectively during a summer morning, noon, and evening (Figure 3-d). In cool to very cold climates, the increase in cooling loads is mostly limited to the summer and fall. Similar trends are observed in light-mass construction, with the notable difference that increases in cooling loads are shifted back toward the noon and evening hours across all seasons.

\section{Discussion}

\section{Annual Changes in Energy Loads: Cost vs. Benefit}

Figure 5 shows changes in annual loads in "heavy mass" shoeboxes as a result of the transition from no direct light (Shading Type A) to varying degrees of direct light

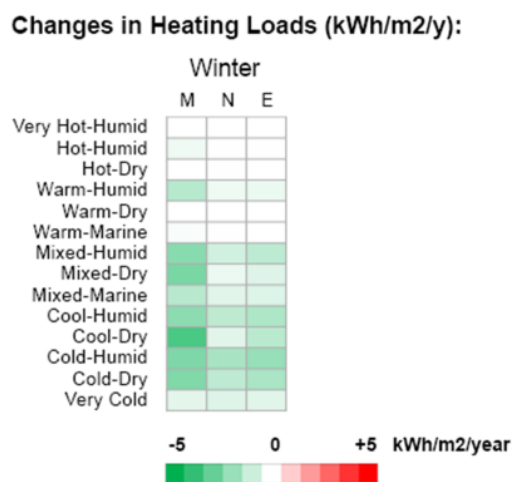

Figure 4: Close-up: Changes in heating loads as a result of admitting direct light (Shading Type A to B) for Heavy Mass: 50\% WWR: Heating Load Changes: Winter

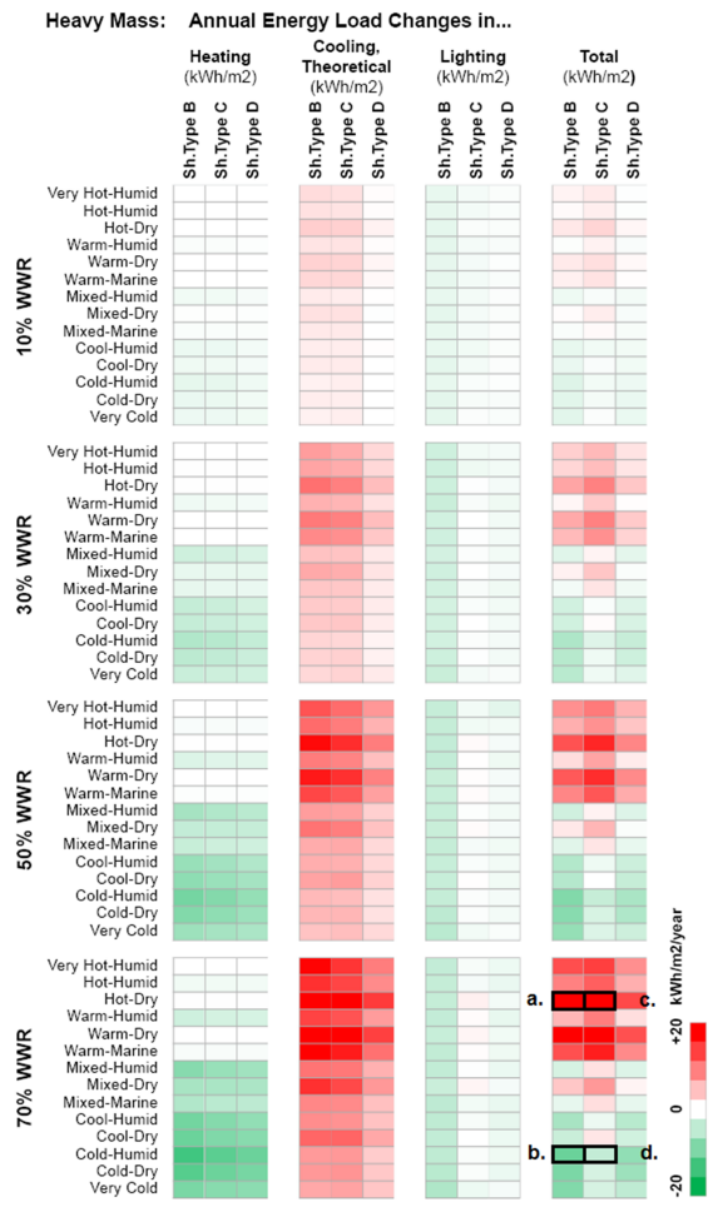

Figure 5: Annual changes in heating, cooling, and electric lighting loads as a result of admitting direct light (Shading Type A to Types B,C,D)

(Shading Types B,C,D). The total energy loads represent the overall benefit or cost of direct light in the interior. Across all WWRs, direct light in the interior will increase total energy demand in very hot to warm climates, despite decreases in electric lighting loads. An increase in WWR will again intensify this trend. Direct light becomes a benefit in most mixed to very cold climates, due to a combined decrease in heating and electric lighting loads. For conditions with no shading whatsoever (shading type B), the most increase in total 
energy loads is in 70\% WWR, Hot-Dry climates (more than $20 \mathrm{kWh} / \mathrm{m}^{2} /$ year; Figure 5 -a), while the largest reduction is found in $70 \%$ WWR, Cold-Humid climates (around $10 \mathrm{kWh} / \mathrm{m}^{2} /$ year; Figure 5-b). However, interior blinds (Shading Type C) will increase total energy loads in most climates (even mixed climates), as electric loads decrease only slightly (or even slightly increase). The said shoeboxes will see a respective increase of nearly $25 \mathrm{kWh} / \mathrm{m}^{2} /$ year (Figure 5 -c) and a decrease of only 5 $\mathrm{kWh} / \mathrm{m}^{2} /$ year (Figure 5-d) with Shading Type C.

Of course, simply examining the total annual increase or decrease in energy loads is a binary approach to the problem. Thus, seasonal and diurnal analysis is still necessary to understand when specifically direct light is thermally harmful.

\section{Adapting the Direct Light Access (DLA) Score}

Using this information, the authors select 6 residential projects across various climates (Figure 6) from an existing set of building models, taking 20 apartment units from each project, to assess the impact of energy demand consideration in the calculation of the Direct Light Access (DLA) score.

As of the current RDS, the DLA gives a full score for a time-bin only if there is a daily average of 2 or more hours of direct light in the interior during that time-bin. Partial scores are possible, in the case that the 2 average daily hours are not met. As there are 12 time-bins, the maximum DLA score is 12 . As an initial exploratory adaptation, the authors suggest that all time-bins in which direct light increases cooling loads and does not reduce heating loads be excluded from the DLA analysis. Thus, all time-bins during which direct light is not useful for thermal purposes would be excluded from the DLA score.

Figure 7 shows the DLA analysis of apartment units in each of the 6 residential projects. The analysis is across all 12 time-bins, and the y-axis reports the average daily hours of direct light for each time-bin. All time-bins that are considered inappropriate for DLA evaluation - i.e. time-bins in which direct light will negatively impact
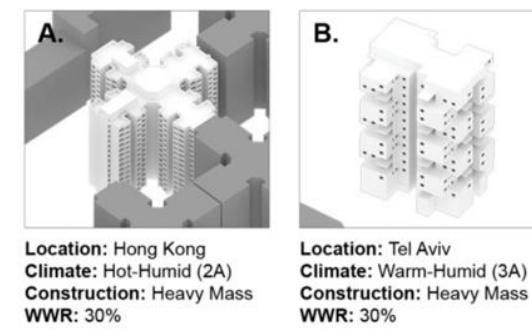
WWR: $30 \%$
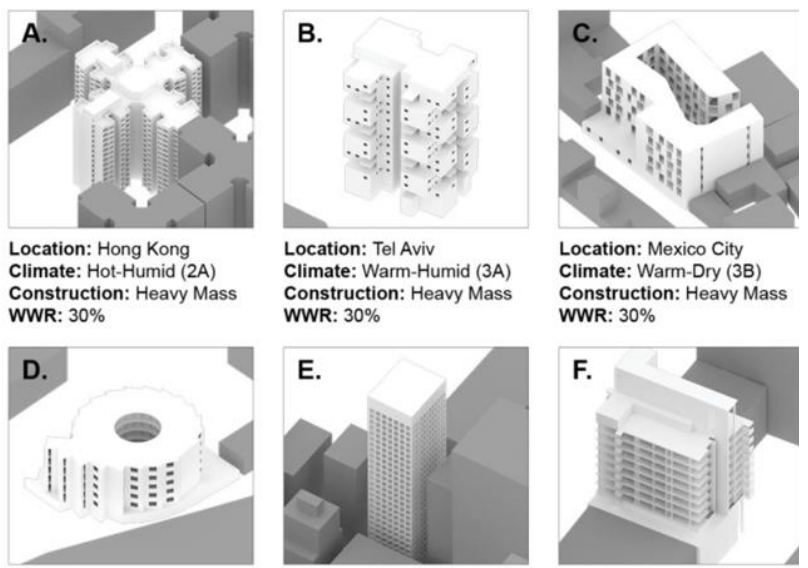

Location: Los Angeles Climate: Warm-Dry (3B) WWR: $10 \%$

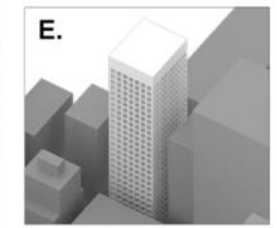

Location: New York d-Humid (4A) WWR: $50 \%$

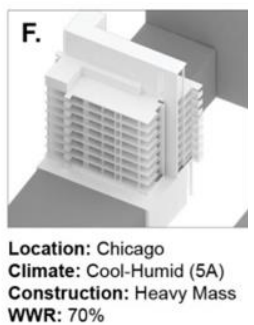

Climate: Cool-Humid (5A)
Construction: Heavy Mas
WWR: $70 \%$
Figure 6: Six residential projects for DLA adaptation
Proj. A: Hot-Humid; Heavy Mass; 30\% WWR

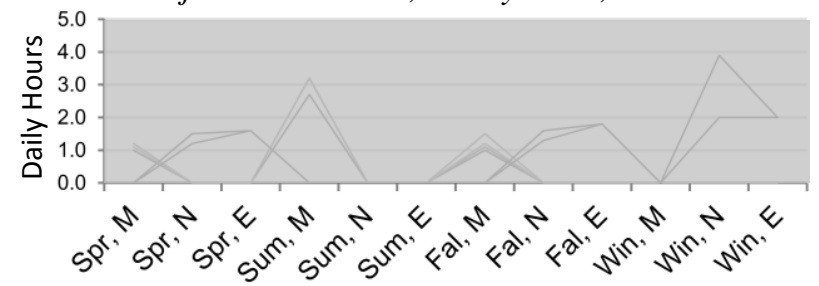

Proj. B: Warm-Humid; Heavy Mass; 30\% WWR

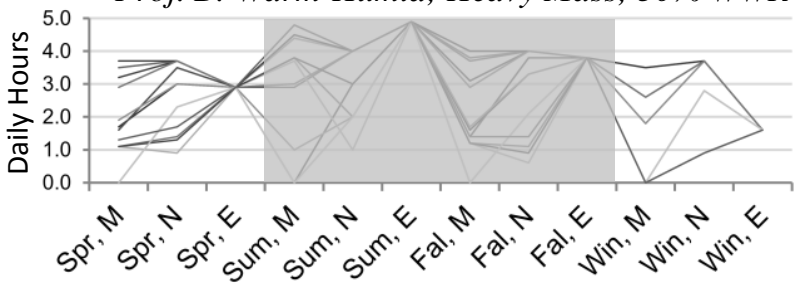

Proj. C: Warm-Dry; Heavy Mass; 30\% WWR

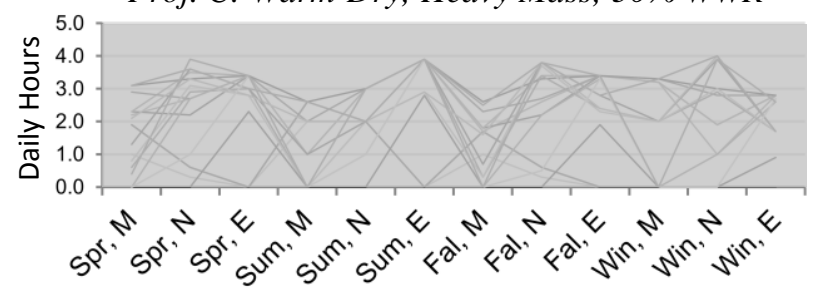

Proj. D. Warm-Dry; Light Mass; 10\% WWR
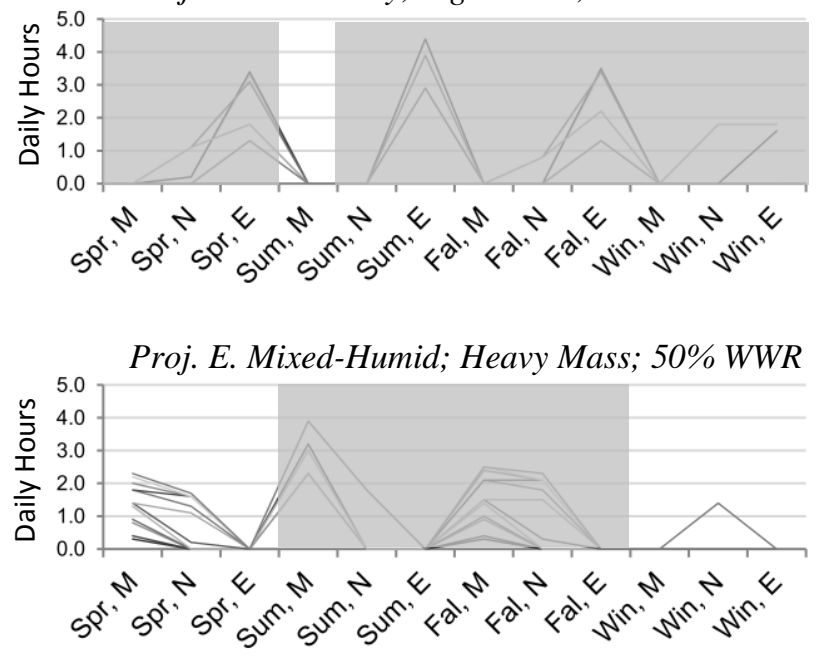

Proj. F. Cool-Humid; Heavy Mass; 70\% WWR

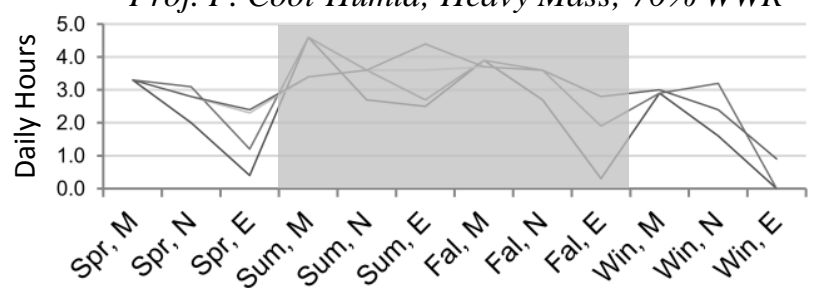

Figure 7: DLA analysis of apartment units in each of 6 residential projects. $Y$-axis reports average daily hours of direct light per time-bin. All time-bins that are considered inappropriate for DLA evaluation are shaded out. 
cooling loads and will not reduce heating loads - are shaded out. As a result, for example, none of the timebins in the Hot-Humid climate (given Heavy Mass, 30\% WWR) will be appropriate for DLA analysis. That is, direct light in the interior will always be harmful in that climate. In such case, exterior balconies would be recommended, as direct light is still vital for various physiological benefits (Fonseca, Tongia, el-Hazmi, \& Abu-Aisha, 1984; Andersen, Mardaljevic, \& Lockley, 2012). In Mixed-Humid and Cool-Humid climates, on the other hand, only the summer and fall time-bins would be inappropriate for DLA analysis.

\section{Future Steps}

The current workflow is a proof-of-concept that is based on simulation data of South-facing shoeboxes. Other orientations and room configurations (such as corner spaces with two facades) need further consideration. East- or West-facing spaces, for example, would likely result in higher cooling loads in the morning and the evening. Further, modeling blind use in residential architecture remains challenging and requires more research as to whether either the LM-83 blind model or a thermally-driven model is adequate. Possibly, an altogether new model that also considers views and privacy concerns, for example, may be needed.

\section{Conclusion}

While direct light access is widely regarded as a qualitative benefit, consequential heat gains may be undesirable in warmer climates. In order to understand the presence of direct light and its impact on heating, cooling, and electric lighting energy loads, this study establishes an EnergyPlus- and Radiance-based simulation framework to identify diurnal and seasonal timeframes during which direct light is either a benefit or a cost in terms of energy loads. The study analysed 448 shoeboxes of varying WWRs, construction types, and shading conditions across 14 climate zones. It is proposed to utilize the presented framework to adapt the DLA so that direct light is rewarded only when there are no negative thermal implications, expanding the applicability of the RDS to a larger variety of climates.

\section{Acknowledgments}

The authors would like to thank the Cornell University Atkinson Center and the Hunter Rawlings Presidential Research Scholars program for funding this research.

\section{References}

Alagöl, F., Shihadeh, Y., Boztepe, H., Tanakol, R., Yarman, S., Azizlerli, H. and Ö Sandalci (2000). Sunlight exposure and vitamin D deficiency in Turkish women. Journal of Endocrinological Investigation, 23(3), 173-177.

Andersen, M., Mardaljevic, J. and S. Lockley (2012). A framework for predicting the non-visual effects of daylight - Part I: photobiology- based model. Lighting Research \& Technology, 44(1), 37-53.

ASHRAE (2014). 90.1-2013 User's Manual: I-P and SI.
Bennet, I. E. and W. O'Brien (2017). Field study of thermal comfort and occupant satisfaction in Canadian condominiums. Architectural Science Review, 60(1), 27-39.

Bennet, I., O’Brien, W., \& Gunay, H. B. (2014). Effect of window blind use in residential buildings: Observation and simulation study. Proceedings of eSIM2014. Ottawa (Canada), May 2014.

De Groot, E., Zonneveldt, L., Paule, B., \& SA, E. (2003). Dial Europe: A decision support tool for early lighting design. Proceedings of the 8th International IBPSA Conference. Eindhoven (The Netherlands), August 2003.

Department of Energy (2004). Commercial Reference Buildings. Retrieved from www.energy.gov/eere/ buildings/commercial-reference-buildings

Dogan, T. (2013). Archsim. Retrieved from www.solemma.com/

Dogan, T. and Y. Park (2018). A critical review of daylighting metrics for residential architecture and a new metric for cold and temperate climates. Lighting Research \& Technology, 51(2), 206-230.

Dogan, T., \& Park, Y. (2017). A New Framework for Residential Daylight Performance Evaluation. Proceedings from Building Simulation 2017. San Francisco (USA), 7-9 August 2017.

Fonseca, V., Tongia, R., el-Hazmi, M. and H. Abu-Aisha (1984). Exposure to sunlight and vitamin D deficiency in Saudi Arabian women. Postgraduate Medical Journal, 60(707), 589-591.

Franzetti, C., Fraisse, G. and G. Achard (2004). Influence of the coupling between daylight and artificial lighting on thermal loads in office buildings. Energy and Buildings, 36(2), 117-126.

German Institute for Standardization (1999). DIN 5034-1 Daylight in interiors - Part 1: general requirements.

Hviid, C. A., Nielsen, T. R. and S. Svendsen (2008). Simple tool to evaluate the impact of daylight on building energy consumption. Solar Energy, 82(9), 787-798.

Illuminating Engineering Society of North America (2012). LM-83-12 IES: Spatial Daylight Autonomy (sDA) and Annual Sunlight Exposure (ASE).

Jakubiec, J. A. and C. F. Reinhart (2012). The "adaptive zone"-A concept for assessing discomfort glare throughout daylit spaces. Lighting Research \& Technology, 44(2), 149-170.

Kleindienst, S. and M. Andersen (2012). Comprehensive annual daylight design through a goal-based approach. Building Research \& Information, 40(2), 154-173.

Mardaljevic, J., Andersen, M., Roy, N., \& Christoffersen, J. (2011). Daylighting Metrics for Residential Buildings. Proceedings of the 27th 
Session of the CIE. Sun City (South Africa), 11-15 July 2011.

Nabil, A. and J. Mardaljevic (2005). Useful daylight illuminance: a new paradigm for assessing daylight in buildings. Lighting Research \& Technology, 37(1), 41-57.

Neufert, E. and P. Neufert (2012). Neufert Architects' Data, Fourth Edition. Wiley-Blackwell. Chichester (UK).

Nielsen, M. V., Svendsen, S. and L. B. Jensen (2011). Quantifying the potential of automated dynamic solar shading in office buildings through integrated simulations of energy and daylight. Solar Energy, 85(5), 757-768.

Reinhart, C. F. and J. Wienold (2011). The daylighting dashboard-A simulation-based design analysis for daylit spaces. Building and Environment, 46(2), 386396.

Rockcastle, S. and M. Andersen (2014). Measuring the dynamics of contrast \& daylight variability in architecture: A proof-of-concept methodology. Building and Environment, 81, 320-333.

Shen, H. and A. Tzempelikos (2012). Daylighting and energy analysis of private offices with automated interior roller shades. Solar Energy, 86(2), 681-704.

Solemma LLC. (2016). DIVA. Retrieved from www.solemma.com/

Strømann-Andersen, J. and P.A. Sattrup (2011). The urban canyon and building energy use: Urban density versus daylight and passive solar gains. Energy and Buildings, 43(8), 2011-2020.

Utzinger, M., \& Wasley, J. H. (1997). Building Balance Point. Vital Signs Curriculum Materials Project, University of California-Berkeley, and University of Wisconsin-Milwaukee.

Wienold, J. (2009). Dynamic daylight glare evaluation. In Proceedings of Building Simulation 2009. Glasgow (Scotland), 27-30 July 2009.

Wienold, J. and J. Christoffersen (2006). Evaluation methods and development of a new glare prediction model for daylight environments with the use of CCD cameras. Energy and Buildings, 38(7), 743757.

Xue, P., Mak, C. M. and H.D. Cheung (2014). The effects of daylighting and human behavior on luminous comfort in residential buildings: A questionnaire survey. Building and Environment, 81, $51-59$.

\section{Appendix}

Table A1: Surface reflectance and window transmittance

\begin{tabular}{|c|c|}
\hline Surface Type & Refl. / Tvis \\
\hline Ceiling & $70 \%$ \\
\hline Floor & $20 \%$ \\
\hline Interior Wall & $50 \%$ \\
\hline
\end{tabular}

\begin{tabular}{|c|c|}
\hline Glazing (Double Pane, Low-E) & $65 \%$ \\
\hline (When applicable) Exterior Shading & $35 \%$ \\
\hline Outside ground & $20 \%$ \\
\hline
\end{tabular}

Table A2: Radiance parameters

\begin{tabular}{|c|c|c|c|c|}
\hline aa .15 & ab 5 & ad 2048 & ar 512 & as 1024 \\
\hline
\end{tabular}

Table A3: Interior Dynamic Blinds Parameters

\begin{tabular}{|c|c|}
\hline Min. Number of Sensors for Blind Trigger & 5 \\
\hline Sensor Spacing & $0.6 \mathrm{~m}$ \\
\hline Sensor Min. Distance from Window & $0.1 \mathrm{~m}$ \\
\hline Sensor Max. Distance from Window & $10.0 \mathrm{~m}$ \\
\hline Roller shade total transmission & $4 \%$ \\
\hline Roller shade direct transmission & $1 \%$ \\
\hline Roller shade total reflection & $41 \%$ \\
\hline
\end{tabular}

Table A4: Zone Loads

\begin{tabular}{|c|c|}
\hline People: Density & $0.0283 \mathrm{p} / \mathrm{m} 2$ \\
\hline People: Schedule & $\begin{array}{l}\text { Department of Energy } \\
\text { reference buildings, } \\
\text { midrise apartment, v. } 1.4 \\
\text { 7.2: APT_OCC_SCH }\end{array}$ \\
\hline Equip: Loads & $5.38 \mathrm{w} / \mathrm{m} 2$ \\
\hline Equip: Schedule & $\begin{array}{l}\text { Department of Energy } \\
\text { reference buildings, } \\
\text { midrise apartment, v. } 1.4 \\
\text { 7.2: APT_EQP_SCH }\end{array}$ \\
\hline Lights: Loads & $3.88 \mathrm{w} / \mathrm{m} 2$ \\
\hline Lights: Target & $3001 \mathrm{x}$ \\
\hline Lights: Dimming & Continuous \\
\hline Lights: Schedule & $\begin{array}{l}\text { Department of Energy } \\
\text { reference buildings, } \\
\text { midrise apartment, v. } 1.4 \\
\text { 7.2: APT_LIGHT_SCH }\end{array}$ \\
\hline Heating: Setpoint & $21.1 \mathrm{C}$ \\
\hline Heating: Av. Schedule & All On \\
\hline Cooling: Setpoint & $23.9 \mathrm{C}$ \\
\hline Cooling: Av. Schedule & All On \\
\hline Hum: On/Off & On \\
\hline Hum: Bounds & $20-80 \%$ \\
\hline Mechanical Ventilation: On/Off & Off \\
\hline Natural Ventilation: On/Off & Off \\
\hline Infiltration & $0.3 \mathrm{ACH}$ \\
\hline Hot Water Peak Flow ( $1 / \mathrm{h} /$ person) & 1.667 \\
\hline Coefficient of Performance $(\mathrm{H} / \mathrm{C})$ & 3 \\
\hline $\begin{array}{c}\text { Primary Energy Factor }(\mathrm{H} / \mathrm{C} \text {, } \\
\text { Lighting) }\end{array}$ & 2.2 \\
\hline
\end{tabular}

